\title{
Persinggungan dalam Rampokan; Apresiasi Komik karya Peter Van Dongen
}

\author{
Terra Bajraghosa, M.Sn. \\ Staff Pengajar \\ Program Studi Disain Komunikasi Visual ISI Yogyakarta \\ bajraghosa@gmail.com
}

\begin{abstract}
Rampokan Jawa \& Selebes, is a comic created by Peter Van Dongen, telling a story about Johan Knevel, a Dutch soldier, in his mission looking for Ninih, his childhood nanny back in Netherland-Indies. This comic attracted many Indonesian readers because of two aspects. First, the setting is in Indonesia around the year 1946-1947, which provides readers with old time indis architectures and vintage designs of things. The second one is its clear line style, similar to Herge's 'Tintinesque' style. These tendecies may appear as pseudo-appreciation to the medium.

This essay's goal, departed from Rampokan's intersection with Tintin, and Indonesia history setting, is to find out the proportionally apreciation on comic as a medium. According to David Carrier, one of comic aesthetic quality relies on the ability of the readers to project their desires on the comic they read. In creating the story, comic composition involved the power of color and visual art syle choice to deliver the idea of the story.

From the discussion, two things about Rampokan appreciation are apprehended. The location and time setting visualization which based on deep research became the main power of this Rampokan comic; representing narrative environment that projected reader's desire: the detailed visualization of the young Indonesia. The choice of clear line style, combined with color composition as an emblematic presentation enabled the delivery of multi plots narratives. Combination of the setting as an observation result and detail art style, provide readers to reasonably believe the storyworld created by Peter Van Dongen. Rampokan's appreciaton quality based on the well-crafted storytelling through well-constructed story-world which enabled readers to follow its fictional or even surrealistic plot twists unconditionally.
\end{abstract}

Keywords: Comic, Appreciation, Aesthetic, Rampokan Jawa \& Selebes

Relevance to Visual Communication Design Practice: Encoding or creation of code in comic medium can be obtained through color composition and choice of graphic-style as materialistic tool to emphasize the message.

\section{PENDAHULUAN}

Membincangkan komik Rampokan karya Peter Van Dongen selalu menarik karena komik ini mampu menyedot perhatian banyak pembaca. Bahkan komik ini hampir menjadi cult di kalangan penggemarnya, menurut Farah Wardani pada diskusi ketika Rampokan Jawa \& Selebes diluncurkan di Karta Pustaka Yogyakarta pada pertengahan Agustus 2014. Komik yang diterbitkan Gramedia Pustaka Utama ini dibungkus dengan istilah novel grafis, menyajikan kisah petualangan Johan Knevel yang lahir di Hindia Belanda dan kembali lagi sebagai prajurit dengan latar peristiwa menjelang agresi militer Belanda, tahun 1946-1947. Sebuah upaya untuk mempertahankan Republik Indonesia yang masih muda tetap sebagai wilayah Belanda.

Ketika Belanda membonceng Sekutu, Johan membonceng pasukannya dalam misi rahasianya mencari babu Ninih, pengasuh 
masa kecilnya di Hindia Belanda. Rampokan bagian "Jawa" diawali dengan ketidaksengajaan Johan menjatuhkan rekan dalam kesatuannya, Erik Verhagen, ke laut, ketika masih di atas kapal menuju Batavia. Sesampainya di Batavia, atas ajakan rekannya Frits de Zwart, diperlihatkan kegiatannya yang memanfaatkan logistik militer untuk kepentingan pribadi dengan menjualnya kepada penadah; seorang pemilik kios di Pasar Atom Bandung. Kompleksitas kisah bertambah dengan hadirnya sosok desertir militer Belanda, Burt Dekker, yang mengaku sebagai wartawan bernama Bennie Ribeek. Demi melindungi identitasnya, dalam kegiatan terlarangnya ini Johan dikenalkan sebagai Erik Verhagen, oleh Frits kepada Burt. Identitas palsu inilah yang kemudian menemukan perkembangan kisahnya dalam Rampokan bagian "Selebes”.

Erik Verhagen dilahirkan di Surabaya, dan diperlihatkan pada beberapa bagian komik, melalui dokumennya, atau foto yang disimpan, bahwa ia terlibat dalam pergerakan komunis baik di Belanda maupun Indonesia. Atas dasar hal tersebut, Johan yang dikenal sebagai Erik oleh Burt kemudian dilibatkan dalam gerakan bersama Amat. Amat dan Burt yang dibawa oleh seorang bernama Abu ke Makasar untuk membantu pergerakan di sana, seolah pro pada perjuangan rakyat pribumi namun ada agenda rahasia yang disembunyikan: apakah mereka memang pro rakyat pribumi, apakah mereka menjalankan agenda partai komunis, apakah mereka sekedar mencari untung di masa perang, dan lain sebagainya, yang memang sengaja tidak diungkap lebih lanjut dalam komik ini. Johan tetap meneruskan sandiwaranya sebagai Erik untuk mengamankan posisinya dalam menjalankan misi utamanya: kembali ke kampung halamannya dulu; Makassar, dan mencari Ninih. Di Makasar, identitas Johan mulai dikenali oleh seorang perawat Belanda, teman masa kecilnya, dan lebih jauh lagi terkuak oleh Jonker, petinggi militer Belanda, yang menganggap dia desersi dan memburunya hingga ke persembunyian Sanro, seorang tokoh adat spritualkharismatik, mirip Bissu dalam tradisi budaya Bugis, yang menjadi ikon pergerakan rakyat.

Kisah Johan tersebut dilapis secara apik dengan kisah mengenai pertunjukan Rampokan, atau dikenal juga dengan Rampogan Macan; sebuah acara serupa 'gladiator' versi Jawa yang mengadu macan (dan harimau) dengan kerbau liar di alunalun sebagai perayaan di kerajaan-kerajaan Jawa. Pada bagian inilah judul komik ini kemudian menemukan pengertiannya. Kisah rampokan dalam komik ini cue kemunculannya diawali oleh ingatan masa 
kecil Johan atas cerita rampokan yang dituturkan oleh Ninih. Secara umum, lapisan kisah rampokan ini bisa dipahami sebagai analogi dari kisah utama, yang melihat nasib Johan dan tokoh-tokoh penting lainnya seperti nasib beberapa macan dalam rampokan.

\section{PESONA RAMPOKAN}

Selain pilihan judul yang multi-tafsir dan terkesan eksotis untuk komik Belanda, bahkan ketika diterjemahkan ke dalam Bahasa Indonesia, komik ini juga memiliki pesona lainnya. Hal ini dibuktikan dengan penghargaan Dutch Prize tahun 1999 untuk Penulis dan sekaligus Penerbit Terbaik kategori Book Design. Pada konteks pembaca tanah air, yang paling sering disematkan padanya adalah daya tarik setting lokasi dan waktu. Melalui pemilihan setting ini maka hadirlah pesona Hindia Belanda. Mulai dari arsitektur; gedung-gedung bergaya indis-art deco, semacam bioskop Rex, hadir dengan indahnya. Juga dapat ditemukan gaya disain iklan-iklan pada masa tersebut seperti batu baterai Eveready, Obat (cap) Matjan, dan Kries bier. Kostum dan elemen penunjang lain yang turut mewarnai setting ini, seperti truk produksi lama, becak, penjual makanan keliling, hingga tukang cukur 'di bawah pohon rindang', juga semakin menguatkan pesona ini. Demi kreasi komiknya, Peter menghabiskan 6 tahun untuk memungut indahnya bangunan-bangunan melalui bukubuku lama, mengunjungi museum untuk melihat pakaian tentara, memilih kostum dengan membongkar foto dokumentasi keluarga, hingga datang langsung di kemudian hari ke pulau Jawa dan Sulawesi.

Kelebihan Peter lainnya, dalam menampilkan daya tarik setting tersebut adalah dengan mengerjakan komiknya dengan gaya gambar clear line, yang segera diidentikan dengan gaya gambar Herge terutama melalui seri Petualangan Tintin. Pilihan gaya ini menjadi pesonanya yang kuat pula. Tokoh, karakter utama, bangunan, kendaraan, hingga elemen pendukung lainnya digambar dengan garis-garis yang tegas, rapi, dan detail. Tarikan-tarikan goresannya seolah dikerjakan dengan ukuran poin garis yang seragam dan flat. Herge sendiri yang mengidentikkan gaya gambarnya dengan clear line, diterjemahkan dari la ligneclaire, gaya gambar khas komik Franco-Belgia (Eropa) yang dikembangkan dari tradisi gaya gambar komik anak-anak, merupakan gaya yang mempunyai tarikan garis yang halus, berkesinambungan dengan kontur yang disederhanakan, dan warna yang cenderung terang dan rata, serta menghindari garis yang patah-patah, bentuk yang 'meledak-ledak', 
dan render yang ekspresif (Hatfield dalam Heer \& Worcester, 2009: 144; Assouline, 2009: 22 ).

Petualangan Tintin dan karya Herge yang lain mempunyai basis penggemar yang besar di Indonesia, sehingga dengan cepat Rampokan turut menyedot perhatian setidaknya para penggemar Tintin. Bahkan ketika masih berbahasa Belanda, kelompok penggemar Tintin berupaya untuk membuat Rampokan diterjemahkan ke Bahasa Indonesia. Ketika Rampokan Jawa terbit pertamakali dalam Bahasa Indonesia tahun 2005, para penggemar Tintin pulalah yang memperkenalkannya kepada pembaca awam, baik melalui tulisan di surat kabar maupun milis. Di ranah yang berbeda, masih lekat di ingatan bagaimana gerakan Demokreatif dalam memuluskan jalan Joko Widodo menuju kursi Presiden Republik Indonesia juga memanfaatkan gaya gambar ala Tintin, dan terbukti mampu menarik perhatian banyak pihak secara visual (Prast, Adhitrisna \& Wibowo, 2014).

Peter mengakui Herge, baik secara gaya visual maupun kemauan untuk melakukan riset, sebagai inspirasi terbesarnya. Sejak masih anak-anak ia sudah mencoba gaya Herge ini, sehingga menurutnya gaya tersebut mengalir di dirinya. Secara lebih khusus ia menyebut seri "Tintin dan Lotus Biru" sebagai karya yang memberinya inspirasi. Sebelum Muizentheater (1990), buku pertamanya, Peter bahkan pernah membuat komik strip dengan karakter dari seri Petualangan Tintin sebagai karya homage kepada Herge.

Homage atau penghormatan terhadap pengarang beserta karyanya, dalam pembahasan film sebagai media populer sering muncul dalam koridor 'connectivity'; sesuatu yang mempunyai hubungan dengan sesuatu di media lain. Hubungan ini bisa muncul sebagai unsur hiburan saja, atau bisa juga mempunyai kedalaman makna, yang kemudian kadarnya meningkat sebagai sebuah citra-intertekstual. Salah satu seri Petualangan Tintin yang berjudul "Flight 714", mengambil setting di sebuah pulau bernama Pulau-pulau Bompa, di negara yang disebut Sondonesia, yang dipahami secara geografis sebenarnya terjadi di daerah kepulauan (Sulawesi) di Indonesia, meskipun tidak disebut secara gamblang (Farr, 2001: 184). Konektivitas antara Rampokan dengan Tintin, selain setting lokasi di kepulauan Sulawesi, juga ada pada narasi mengenai sambal dan patung megalith seperti yang ada di Lembah Bada, Taman Nasional Lore Lindu.

Dalam Tintin, sambal hanya disebutkan oleh seorang karakter penjaga, barangkali 
untuk menekankan 'ke-Indonesiaannya'. Sedangkan dalam Rampokan, diperlihatkan bahan-bahannya, teknis membuatnya, kualitas pedasnya, dan khasiatnya dalam sebuah adegan di dapur umum tangsi militer Belanda. Mengenai patung megalith yang berbentuk seperti kepala, dalam Rampokan diperlihatkan bagaimana seorang pribumi gentar ketika melihatnya; yang bisa dilihat bahwa patung tersebut mempunyai kekuatan tertentu (secara kultural) dan menekankan bagaimana mistisnya suasana di pedalaman Makasar. Dalam kreasi Herge, patung kepala tersebut diolah secara naratif, sebagai sebuah pintu putar rahasia yang mengarah pada sebuah ruangan tersembunyi. Konektivitas tersebut bisa jadi hanya kebetulan, sebagai sebuah logis dunia-cerita. Namun ketika khalayak Tintin juga kemudian membaca Rampokan, konektivitas yang muncul bisa memberi arti yang berbeda. Pembaca Rampokan yang tidak pernah membaca Tintin seri 'Flight 714 ' tidak akan melihat hubungan ini sebagai sesuatu yang menarik, selayaknya sebuah citra intertekstual yang tidak dikenal rujukannya: ia tidak menyerap kualitas citra lainnya.

Kedua daya tarik komik Rampokan tersebut; (1) setting cerita yang bersinggungan dengan sejarah, dan (2) pilihan gaya gambar clear line yang bersinggungan dengan gaya gambar Herge dalam Tintin menyedot perhatian (terlalu) besar. Dalam pengertian bahwa hal ini bisa mengarah pada sebuah apresiasi semu; yang tidak melihat daya komik Rampokan secara utuh. Bukan suatu kesalahan, namun ada baiknya diperhatikan pula kekuatan-kekuatan lain dari komik Rampokan ini sehingga suatu karya komik bisa diapresiasi secara lebih proporsional. Berdasarkan pemahaman tersebut, tulisan ini tetap hendak menyoroti dua persinggungan tersebut dan melihat potensi yang terkandung di dalamnya.

\section{RAMPOKAN DAN TINTIN}

Gaya visual clear line yang dipilih oleh Peter, akan selalu dikaitkan dengan Herge dan Tintin. Bukan kebetulan pula jika Joost Swarte, komikus Belanda, yang memunculkan istilah Klare Lijn (clear line), bertindak sebagai visual advisor dalam Rampokan. Joost dan Peter disebut sebagai penerus gaya gambar komik yang menampilkan garis-garis yang rapih dengan ukuran yang sama ini. Kemiripan gaya ini di satu sisi mampu mengangkat komik karya Peter namun di sisi lain justru menutupi keunggulannya yang membedakannya dengan karya-karya Herge.

Selayaknya tradisi komik Eropa, gaya clear line memang banyak dipakai pada komik petualangan tokoh baik hati yang siap 
untuk mengalahkan kejahatan, dengan kisah yang berbobot namun tidak berat, dengan kecenderungan menampilkan karakter bergaya kartun pada gambar latar belakang yang detail dan lebih realis (Duncan \& Smith, 2009: 297, Hatfield dalam Heet \& Woochester 2009: 145). Tintin dan sosok karakter lain ditampilkan Herge dengan gaya kartun, sehingga ketika difilmkan dengan rujukan aktor manusia, berjudul The Adventures of Tintin (2013), wajah dan proporsi tubuhnya pun dikartun-kartunkan dalam teknik animasi 3D. Bila diperhatikan karakter manusia dalam komik Rampokan selalu digambar proporsional dan realis. Anggaplah hal tersebut sebagai clear line versi Peter Van Dongen yang membedakannya dengan Tintin / Herge.

Gaya visual dan teknik pengerjaan komik, seperti clear-line ini menurut Hatfield (dalam Heer \& Woocester, 2009: 144-147) adalah merupakan salah satu unsur, -selain disain, tata letak, penampilan tekstual fisik,dari sebuah komik sebagai sebuah dimensi objek materialitas. Kualitas materialitas ini, ketika diolah dengan baik, dapat dimanfaatkan untuk mengomunikasikan, atau memberi penekanan pada makna yang ingin disampaikan pada sebuah teks komik. Sebagai sebuah karya sastra-gambar yang dihasilkan oleh (seorang) penulis, komik menyampaikan makna-pesan dari kepada pembaca dengan berbagai retorika, yang salah satunya adalah persuasif. Dalam menyampaikan persuasinya, pilihan gaya clear line mencakup dua syarat sekaligus yakni kredibilitas (ketrampilan Peter menggambar) dan kemampuan menjaga emosi (gaya yang bersih, cenderung datar namun padat dengan kode). Syarat ketiga, yakni bukti-bukti, secara umum hadir pada elemen-elemen setting yang diperoleh Peter dengan observasi yang tekun. Syarat-syarat ini diajukan oleh Aristoteles dalam Rethorica (Keraf, 2010: 120-122)

Melalui pandangan ini, clear line dalam Rampokan bisa dilihat sebagai upaya Peter dalam menghadirkan secara utuh duniacerita yang realis, Hindia Belanda pada masamasa terakhirnya. Dunia-cerita realis ini kemudian ia gunakan sebagai ruang hidup karakter-karakternya yang penuh beban secara psikologis, dengan pola hubungan di antara mereka yang rumit, dan sesekali bahkan terkesan surealis. Kesuramankesuraman yang ada pada sisi narasi, yang secara sekilas tidak terwujud langsung dalam pilihan visualnya mengarah pada: (1) pilihan gaya realis memudahkan pembaca untuk menciptakan closure dengan lebih baik, menyediakan pendekatan-pendekatan bagi pemahaman plot cerita yang tidak sederhana, 
dan/ atau (2) gaya realis secara persuasif memberikan rasionalisasi kepada pembaca sehingga secara simultan menerima kerumitan, kesuraman, atau ketidak-logisan narasi yang dibangun oleh Peter.

Cerita dalam Rampokan menyajikan plot yang berlapis, yang kadang bahkan muncul bersamaan pada satu halaman, walaupun pada dasarnya untuk tetap mendukung plot utama. Sebagai contoh pada halaman 147 yang menampilkan 4 alur kisah beda tempat dan beda waktu antara (1) peristiwa perayaan perburuan yang dilakukan Sanro, (2) Johan yang pingsan, (3) kilas balik anak kecil indo yang dibunuh, (4) serta pasukan Belanda yang hendak menyergap. Jalinan kisah dalam Tintin berjalan lebih sederhana dan linier; secara umum menampilkan suatu situasi dalam satu waktu saja.

Pada bagian "Selebes", di antara kisah yang memang mengambil setting lokasi di Makasar, diselipkan kisah mengenai perburuan macan secara on-off, atau selangseling. Peristiwa perburuan ini tetap terjadi di Jawa, dan bahkan terjadi pada dimensi waktu yang berbeda. Secara apik Peter menjalinnya dengan narasi Johan yang mencari Ninih, atau persiapan Burt Dekker dan Amat melakukan pemberontakan, yang terjadi di Makasar pada masa kini (sesuai dunia-cerita). Pembaca yang akrab dengan alur komik yang linier akan dibuat bingung dengan multiplot ini, bahkan bisa saja mengira perburuan macan tersebut terjadi pada ruang dan dimensi waktu yang sama dengan peristiwa petualangan Johan. Herge menyampaikan cerita melalui aksi Tintin, sedang Peter menyampaikan cerita bukan hanya melalui aksi Johan saja, namun juga melalui ingatannya. Seperti telah disebutkan, ingatan Johan akan kisah yang disampaikan oleh Ninih inilah yang membangun hubungan antara judul 'Rampokan' dengan cerita dalam komik ini. Dalam Takdir (Carey, 2014) disampaikan bagaimana para penguasa Belanda di Jawa pada masa sebelum Perang Jawa dibuat resah karena ketika rampokan macan di Alun-alun Selatan Yogyakarta menunjukkan perangai si macan yang tak biasa. Ia tidak membunuh kerbau yang telah dilukai. Sedang macan lainnya lari ke luar arena dan dibunuh di belakang panggung Sultan. Metafora bahwa macan adalah Belanda ini yang dimanfaatkan oleh Peter dalam komik Rampokan. Secara teknis ia menyebut pernah membuat komik mengenai rampokan macan namun tidak bisa dikembangkan untuk banyak halaman. Lalu ia mengarang kisah rekaan baru mengenai Johan dan menyelipkan kisah mengenai rampokan macan di antaranya. Judul Rampokan tetap ia pertahankan selain karena 
nilai keunikan yang tinggi namun ia juga terbukti mampu mengembangkannya sebagai penjalin kisah, dari awal, pertengahan, perpindahan dari bagian Jawa ke Selebes, dan hingga ke bagian akhirnya. Nasib Johan sedikit banyak tercermin pada nasib si macan. Selain macan, sebenarnya hadir pula sosok hewan lain yaitu dua burung bangau bluwok (suku Ciconidae) yang sejak awal hingga akhir kisah muncul dalam beberapa panel, baik sebagai objek utama maupun pelengkap, dan di antara panel. Bahkan ada beberapa panel yang khusus menampilkan close-up matanya. Kadang ia hadir seiring dengan teks narasi, kadang sebagai pelengkap setting, kadang seolah tak terpengaruh pada adegan yang ada. Kemunculannya seolah tak berpola bila dibandingkan dengan pola munculnya sosok macan. Pola kemunculan gambar pada tiap panel yang berhubungan, meski tidak secara langsung, bisa dilihat sebagai sifat kohesi yang menghubungkan suatu sekuensi panel untuk menyampaikan cerita (Saraceni, 2003: 36-39). Secara kohesif apa yang dirangkai oleh given information, -informasi yang berulang pada rangkaian panel-, berupa dua bangau ini tidak menghubungkan apapun. Sehingga kohesi yang dihadirkan oleh kedua bangau ini dipahami lebih mengarah pada hal simbolik dibandingkan dengan sekuensi cerita. Karakter wajahnya yang bermata seperti memicing dan berkepala botak membuat penampilannya menjadi semisterius perannya dalam narasi Rampokan. Kehadirannya tidak berpengaruh pada jalannya cerita, namun bila dilihat dari ekspresinya yang seperti mengamati, ia (seolah) menjadi representasi dari narator yang berada di luar cerita. Sosoknya juga menjadi penguat unsur misteri dalam keseluruhan kisah karena dari semua peristiwa antar lokasi, antar waktu, antar dimensi (nyata-mimpi), antar tokoh, justru sosok dua bangau ini saja yang muncul. Ketika bangsa barat (Belanda) umumnya lebih percaya pada rasional-material dibandingkan dengan takhayul, sosok Johan sebagai tokoh utama berada di antaranya; dan bangau bluwok ini seperti menegaskan sisi takhayul-mistis yang lekat dengan Jawa dan Selebes.

Pilihan warna tan (coklat muda, mendekati krem, C:0, M:14, Y:33, K:18) yang hanya diterakan pada beberapa bagian juga menjadi kekuatan komik Rampokan. Menyebut alasan utamanya karena motif ekonomi, pilihan duotone ini justru mampu memberi kekhasan pada karya Peter. Pada bagian Jawa ia menerakan tone secara manual selama dua bulan dengan memotong langsung film warna. Sedang pada bagian Selebes, toning ia kerjakan secara digital dan 
hanya memakan waktu dua minggu. 'Sungguh suatu kemajuan', selorohnya dalam sesi diskusi. Dalam mengreasikan kode-kode pada komik, bahkan pada setiap panelnya, komposisi menjadi sangat penting, dan warna adalah salah satunya. Warna dapat digunakan untuk fungsi-fungsi naratif, menekankan emosi pada suatu kisah, dan bahkan pemakaian hitam-putih saja dapat memberikan pengaruh pada makna kisah (Duncan \& Smith, 2009: 141).

Warna yang dihadirkan pada Rampokan tidak semata sebagai warna objek atau kesan gelap-terang cahaya, Peter menerakan tone sebagai warna yang juga memaparkan gagasan. Ia memilah antara penggambaran kisah aktual, kilas balik, atau bahkan mimpi melalui pemakaian kombinasi warna berbeda. Misalnya kisah mengenai rampokan macan yang didominasi warna hitam-putih saja dengan blok hitam pada beberapa bagian dan kotak narasi berwarna tan. Lalu mimpi yang ditunjukkan dengan dominasi background blok hitam, dengan kotak narasi hitam teks putih. Tentunya pemilihan warna ini juga tidak kemudian bersifat kaku, namun bisa ia belokkan untuk mengecoh pembaca dengan menggabungkan misal antara (warna) mimpi, (warna) kilas balik dan (warna) kisah aktual, seperti ketika tokoh Pawang Rampokan dan Erik Verhagen melayang bersama, atau ketika macan yang seharusnya pada dimensi kilas balik, seolah berada pada dimensi aktual hanya karena kini ia berwarna tan setelah sebelumnya hanya hitam-putih.

Komik-komik yang ambisius dan banyak dibicarakan justru bercerita tanpa kehadiran warna primer; hitam, putih atau setidaknya warna lembut (tone sepia, tinta hijau), menjadi warna yang emblematis dari komik serius. Warna dipercaya mampu menghadirkan subyek secara formal, sedangkan dalam hitam dan putih, ide pesan justru mampu dikomunikasikan secara langsung (Duncan \& Smith, 2009: 141-142, McCloud, 2000: 189, 192). Rampokan memberi contoh nyata bagaimana kekuatan naratif komik dapat dicapai melalui penerapan dan kombinasi warna, meskipun ia terbatas pada satu warna saja di luar hitam dan putih (kertas).

\section{RAMPOKAN DAN KISAH SEJARAH}

Persinggungan lintasan yang kedua adalah sejarah. Keterkaitan komik ini dengan kisah sejarah yang terjadi di Indonesia, turut menjadikan komik ini semakin digemari, dan dianggap layak untuk dibuatkan terjemahan versi Bahasa Indonesianya. Secara umum komik Eropa non Bahasa Inggris dianggap berhasil bila diterbitkan ke dalam edisi Bahasa Inggris dan, atau dalam edisi Bahasa Perancis. 
Latar cerita peristiwa kembalinya Belanda ke Indonesia, yang didukung penggambaran yang realis mulai dari pakaian, kendaraan, bangunan, hingga elemen kecil seperti poster di rumah makan, atau mata uang kertas, membuat Rampokan seolah-olah komik dengan muatan sejarah. Di sisi lain, beberapa komik Indonesia yang diintensikan sebagai komik sejarah memang mencoba memunculkan gaya gambar realis. Misalnya komik Merebut Kota Perjuangan (1983) dan Pertempuran Makasar (1985), dan pada era terkini beberapa karya Mansyur Daman (Man) melalui komik-komik biografi pahlawan nasional yang disalurkan lewat museum-museum milik pemerintah di Jakarta (2011-sekarang).

Dalam pembahasan sebelumnya mengenai syarat sebuah retorika bersifat persuasif, bukti-bukti yang menjadi syarat penting untuk meraih kepercayaan pembaca dihadirkan Peter melalui hadirnya 'artefakartefak' Hindia Belanda dalam hampir setiap lembar komiknya. Begitu juga pada bagian "Selebes", yang selain memuat bangunan bergaya indis, juga menampilkan rumahrumah adat khas Sulawesi Selatan. Dalam membangun persuasi, bukti-bukti bisa saja tampil minimal namun harus dipergunakan seefektif mungkin (Keraf, 2010: 121). Efektivitas ini diterjemahkan Peter dengan menghadirkan elemen setting dengan penuh pesona: detail, terampil, dan melibatkannya dalam cerita. Hasil risetnya diterjemahkan sebagai bukti atau fakta dalam membangun cerita, yang ia hadirkan bukan untuk mencari pembenaran namun untuk menuju pada kesepakatan dengan pembaca mengenai lokasi, waktu, budaya, dan logis cerita. Seturut pendapat Scott McCloud (2006: 176179), Peter mampu menghadirkan pesona tersebut melalui komiknya karena ia menghadirkan bukan hanya sebuah background gambar saja, melainkan sebuah environment tempat hidup karakter komiknya. Terlebih dengan riset yang ia lakukan, apa yang hadir kemudian bukan sekedar gambar detail, tetapi sebuah penghubung antara karya komiknya dengan kenangan dan pengalaman yang dimiliki oleh pembaca. Kedekatan pembaca terhadap apa yang dimunculkan dalam komik, terlebih fantasi atau harapan ideal, menurut David Carrier (1995: 85, 92) menjadi poin penting dalam ranah estetika komik. Menurutnya komik adalah soal pembaca, yang merefleksikan harapan mereka ke dalam komik tersebut. Meskipun sebagian besar pembaca komik ini tidak hidup atau mengalami peristiwa di tahun 1946-1947, kerinduan akan visual Indonesia di masa lampau, terlepas dari kondisi ekonomi 
masyarakat, keadaan politik dan status koloni, menjadi poin utama dalam publik memberi apresiasi kepada komik Rampokan ini.

Kisah dalam komik Rampokan ini sepenuhnya fiksi menurut Peter, meski beberapa tokoh ia ciptakan berdasar pada tokoh yang nyata semisal kakeknya yang memang seorang prajurit bernama depan Johan yang bertugas di Hindia Belanda, ditawan dan kemudian dipancung oleh tentara Jepang. Kisah mengenai babu atau nyai, juga menarik perhatiannya, sehingga tokoh babu Ninih maupun Lisa Mangar muncul. Secara keseluruhan niatnya mengerjakan komik ini terinspirasi dari kisah-kisah mengenai Indonesia yang disampaikan oleh Neneknya yang berasal dari Manado, dan perbincangannya dengan Ibunya yang lahir di sana.

Pada beberapa komik Eropa (FrancoBelgia) yang terkenal, meramu kisah fiksi namun menghadirkan kilasan sejarah, baik itu tokoh maupun peristiwa tertentu, memang jamak ditemui. Kebanyakan komik tersebut mendompleng pada kisah yang dicatat sejarah, namun tidak lalu berarti menjadikan komik tersebut sebagai komik sejarah. Julius Caesar dan Cleopatra hadir dalam seri komik Asterix, bahkan menjadi tokoh sentral dalam beberapa serinya. Lihatlah Asterix dan Obelix dalam 'Asterix dan Cleopatra', yang turut membangun patung Sphinx dan seolah-olah turut menentukan banyak kebijakan. Termasuk dalam hal ini menunjukkan kenapa hidung Sphinx cepat rusak; akibat ulah Obelix yang terjatuh dan terpaksa berpegangan pada hidung tersebut, yang lalu copot, dan kemudian secara diam-diam ia sambung kembali. Seri Lucky Luke menghadirkan tokoh nyata yang tercatat dalam sejarah, seperti misalnya Jesse James, Calamity Jane dan Sarah Bernhardt. Formula serupa pernah dicoba oleh komikus Indoensia Dwi Koen melalui komiknya yang berjudul Sawung Kampret (2000). Secara tipologis bisa jadi Rampokan mencoba mengikuti pola tersebut, namun mereduksi habis kadar humornya atau kadar 'bahwa yang ada pada masa kini akibat ulah salah satu tokoh komik'. Dan meningkatkan kadar keseriusannya: secara sadar bersandar pada peristiwa sejarah namun juga secara kreatif bisa mengarang cerita apapun.

Dilihat dari 'kesuraman' jalan ceritanya maupun visual yang nampaknya simpel namun menyimpan banyak kerumitan, komik ini justru lebih dekat pada kategori Noir. Tidak ada yang menang dalam kisah ini, ending-nya tidak happy. Pun dengan Johan yang bertindak seperti layaknya antihero, bersembunyi di balik penyangkalan- 
penyangkalan, maupun keinginankeinginannya yang terpendam, yang membuatnya serba salah dalam bertindak. Bahkan sejak awal cerita. Begitu pula kepahitan-kepahitan yang harus diterima oleh tokoh-tokoh lain dalam kisah ini. Buku War Graphics (Conroy, 2009) yang merupakan rangkuman review komik-komik bertema sejarah perang, bisa dilihat sebagai pembanding. Sebuah judul komik bisa dilihat sebagai sebuah 'komik sejarah perang' bila memang menempatkan kisah perang terebut sebagai kisah utama. Meskipun berupa investigasi, atau opini sekalipun (War is Boring, Palestine), kisah perang menjadi pokok bahasannya. Peter dalam Rampokan lebih fokus mendongeng mengenai hubungan-gelap dan salah-sangka antar tokoh, dibanding menjelaskan detail mengenai latar belakang si tokoh dan posisinya dalam peta sejarah. Pembaca dianggap telah pandai dalam melakukan closure terhadap tanda-tanda visual yang ia tebar. Peristiwa sejarah Agresi Militer kemudian ia rasa mampu dijadikan sebagai wadah untuk menampung semua kisahnya, tanpa harus menjadikan komik ini sebagai komik mengenai peristiwa agresi militer tersebut.

Johan Knevel dan peristiwa agresi militer di Indonesia sama seperti Asterix dan pembangunan patung Sphinx. Para pembuat komik ini, termasuk Peter menempatkan tokoh-tokoh rekaannya seperti benar- benar ada dalam lintasan sejarah, namun tidak sebagai tokoh utama yang tecatat dalam buku-buku sejarah. Kisah Johan dan para tokoh dalam kisah ini bila memang benar terjadi, bisa dilihat sebagai petite histoire atau 'sejarah kecil'. Suatu istilah yang menurut Rosihan Anwar digunakan untuk melihat suatu peristiwa kecil yang bermakna dalam kehidupan seseorang namun ikut mengalir dalam suatu arus sejarah besar suatu negara atau bangsa.

Rampokan menampilkan goof berupa kesalahan-waktu. Pada bagian Selebes yang mengambil setting pada bulan Desember tahun 1946 diceritakan beberapa tokoh yang berbuka puasa, ada anak-anak, yang bermain petasan, dan ucapan dialog yang menyebutkan "...padahal ini bulan puasa" yang bisa dipahami sebagai kode [bulan Ramadhan]. Di halaman bagian lain ditunjukkan sekelompok orang Belanda merayakan Natal di gedung societet, dengan Jonker yang terpaksa pamit dari acara tersebut untuk bisa menginterogasi tahanan di rumah sakit. Melalui pemahaman bahwa kalender Islam lebih pendek sekitar 10 hari dibandingkan dengan kalender masehi; jika Proklamasi kemerdekaan Republik Indonesia 
17 Agustus 1945 dikumandangkan pada bulan Ramadhan, maka pada tahun 1946 tentunya bulan Ramadhan tidak akan jauhjauh dari bulan Agustus. Sedangkan Natal, seawal apapun dirayakan, tidak akan dimulai sebelum bulan November. Hal ini menguatkan sisi fiksional dari Rampokan. Intensi Peter untuk menyeiringkan perayaan Natal di pulau tropis dengan bulan Ramadhan dalam ceritanya merupakan sebuah upaya yang bisa dilihat lebih bersifat puitik, dibandingkan dengan upaya historis.

\section{PENUTUP}

Rampokan Jawa \& Selebes karya Peter Van Dongen memang akan selalu dikaitkan dengan Tintin, dan dibincangkan di antaranya karena menampilkan suasana Pasar Atom di masa lalu, adegan potong rambut di bawah pohon, atau indahnya bangunan bergaya indis, memori nostalgia yang memang hanya bisa disaksikan kini melalui buku-buku atau arsip sejarah.

Apresiasi tinggi pada ramuan kisah fiksisejarah komik Rampokan Jawa \& Selebes disematkan pada kemauan komikusnya untuk melakukan riset dan pengamatan mendalam untuk menghasilkan akurasi pada pilihan setting dan elemen pendukung cerita yang lain yang dituangkan melalui gaya clear line yang canggih. Ketika pada umumnya gaya clear line diterapkan pada komik dengan cerita tentang jagoan yang berhati baik dan bisa mengalahkan musuhnya, Peter memilihnya sebagai aspek materialitas untuk menunjukkan setting lingkungan, duniacerita, yang hidup dan detail. Hal ini ditunjukkan dengan penggambaran sosok manusia yang realis, alih-alih menampilkannya secara kartunal.

Pola kreasi Rampokan menempatkan penyampaian cerita sebagai hal yang utama; detail (melalui gaya clear-line) diusahakan sedekat mungkin dengan kenyataan (hasil riset) yang dibayangkan pembaca. Dengan modal ini, logis dunia-cerita sudah terbangun; tanpa maksud mendikte untuk mempercayainya sebagai kisah nyata atau sejarah. Persuasi logis dunia-cerita yang telah terbangun menjadi fondasi Peter van Dongen untuk luwes menyampaikan narasi miliknya. Fiksi atau fantasi sekalipun pembaca telah menaruh percaya padanya, dan siap untuk menerima kejutan-kejutan atau bahkan twist, yang tidak ada dalam sejarah, atau bahkan yang tidak masuk akal sama sekali. Pada bagian inilah kualitas Rampokan bertengger. Sekiranya persinggungan-persinggungan Rampokan dapat dipahami utuh dan dapat meningkatkan pengalaman-estetis membaca komik, untuk dapat melihatnya lebih jauh 
dari sekedar 'komik mirip Tintin yang ada cerita Indonesianya'.

\section{DAFTAR PUSTAKA}

[1] Assouline, Piere. 2009. Herge; The Man Who Created Tintin, terj: Charles Ruas, Oxford University Press, Oxford.

[2] Carey, Peter. (2014). Takdir. Kepustakaan Populer Gramedia, Jakarta.

[3] Carrier, David. (2000). The Aesthetics of Comics, Pennsylvania State University Press, Pennsylvania.

[4] Conroy, Mike. (2009). War Stories; A Graphic History, HarperDes

[5] Dongen, Peter Van. (2014). Rampokan Jawa \& Selebes, terj: Bernie Lim, Gramedia Pustaka Utama, Jakarta.

[6] Duncan, Randy \& Matthew J. Smith. (2009). The Powers of Comics; History, Form \& Culture, Continuum, New York.

[7] Farr, Michael. (2011). Tintin The Complete Companion (Tintin Panduan Lengkap), terj: Yoga Nandiwardhana, Gramedia Pustaka Utama, Jakarta.

[8] Hatfield, Charles, "Art Of Tensions" dalam Heer, Jeet \& Kent Worcester. (2009). A Comic Studies Reader, University Press of Mississippi, Mississippi.

[9] Keraf, Gorys. (2010). Argumentasi dan Narasi, Gramedia Pustaka Utama, Jakarta.

[10] MCloud, Scott. (1993). Understanding Comics: The Invisible Art, Thundra Publishing, Northhampton. (2006). Making Comics: Storytelling Secrets oc Comics, Manga and Graphic Novels, Harpers, New York

[12] Prast, Hari, Yoga Adhitrisna \& Satriyo Wibowo. (2014). Demokreatif; Kisah Blusukan Jokowi, POP, Jakarta.

[13] Saraceni, Mario. (2003). The Language of Comics, Routledge, London \& New York.

\section{LAMPIRAN}
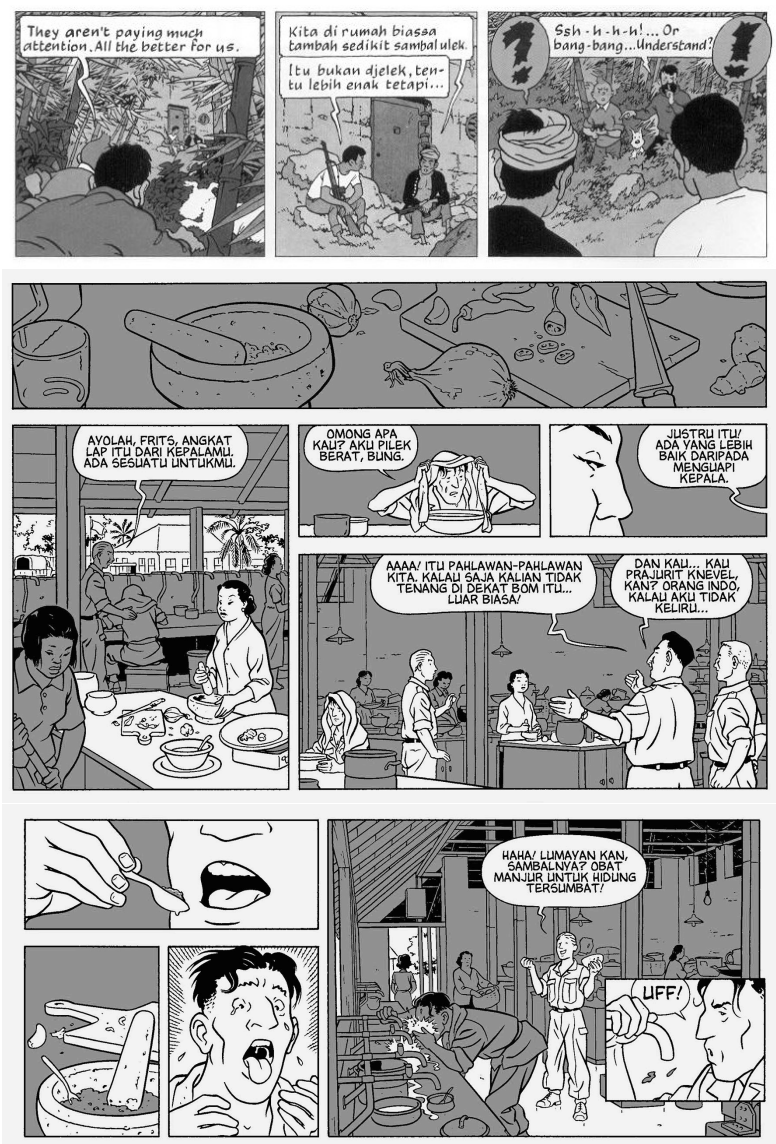

Gambar 1 Keterhubungan: narasi tentang sambal, pada komik Tintin dan Rampokan. Sumber: Herge. (1980). The Adventures of Tintin; Flight 714, Mammoth Book, h.30, Dongen, Peter van. (2014). Rampokan Jawa \& Selebes; GPU, h. 33, 35 

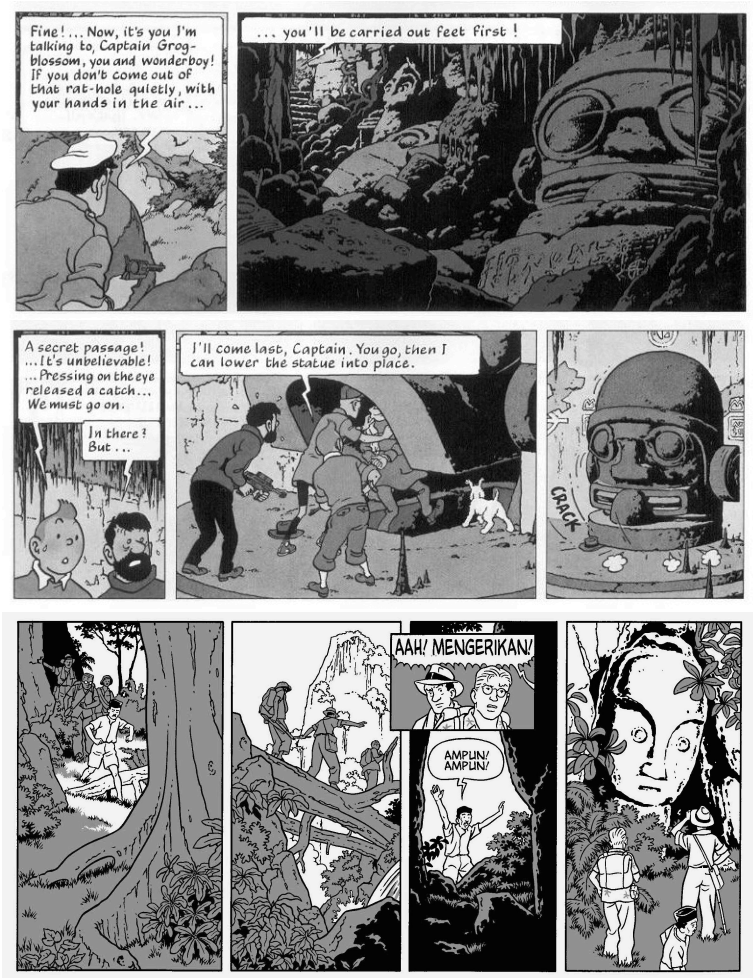

Gambar 2 Keterhubungan: narasi tentang patung kepala megalith, pada komik Tintin dan Rampokan. Sumber: Herge. (1980). The Adventures of Tintin; Flight 714, Mammoth Book, h.40, 43, Dongen, Peter van. (2014). Rampokan Jawa \& Selebes; GPU, h. 33, 35

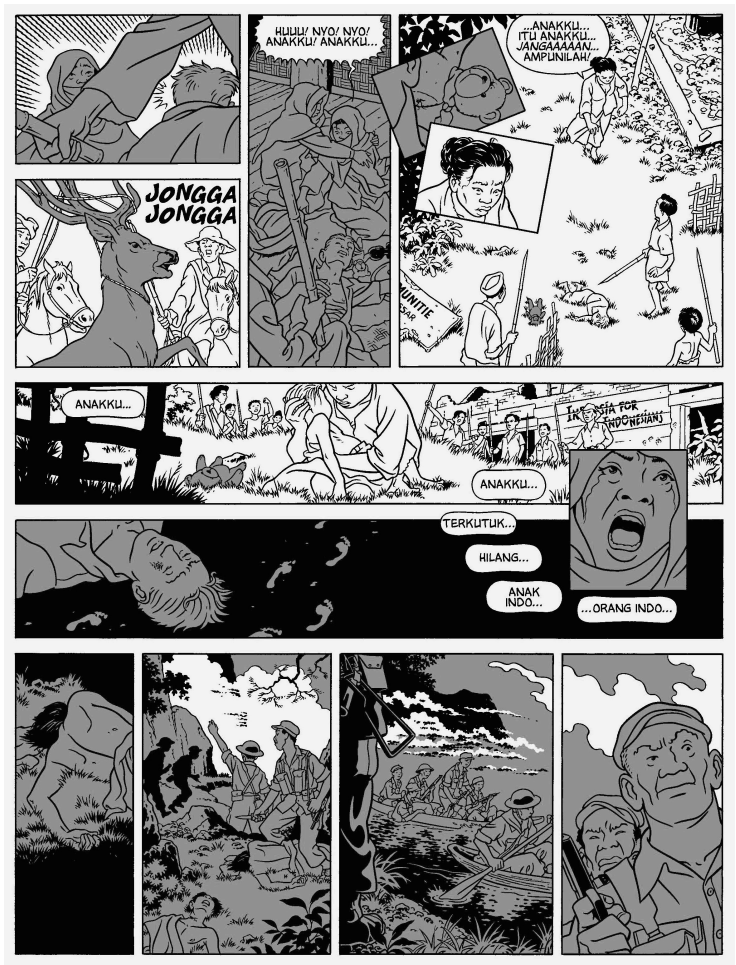

Gambar 3 Satu halaman menunjukkan narasi multi-subplot; beda lokasi, dan beda jaman, dalam satu sekuensi. Sumber: Dongen, Peter van. (2014). Rampokan Jawa \& Selebes; GPU, h. 147 


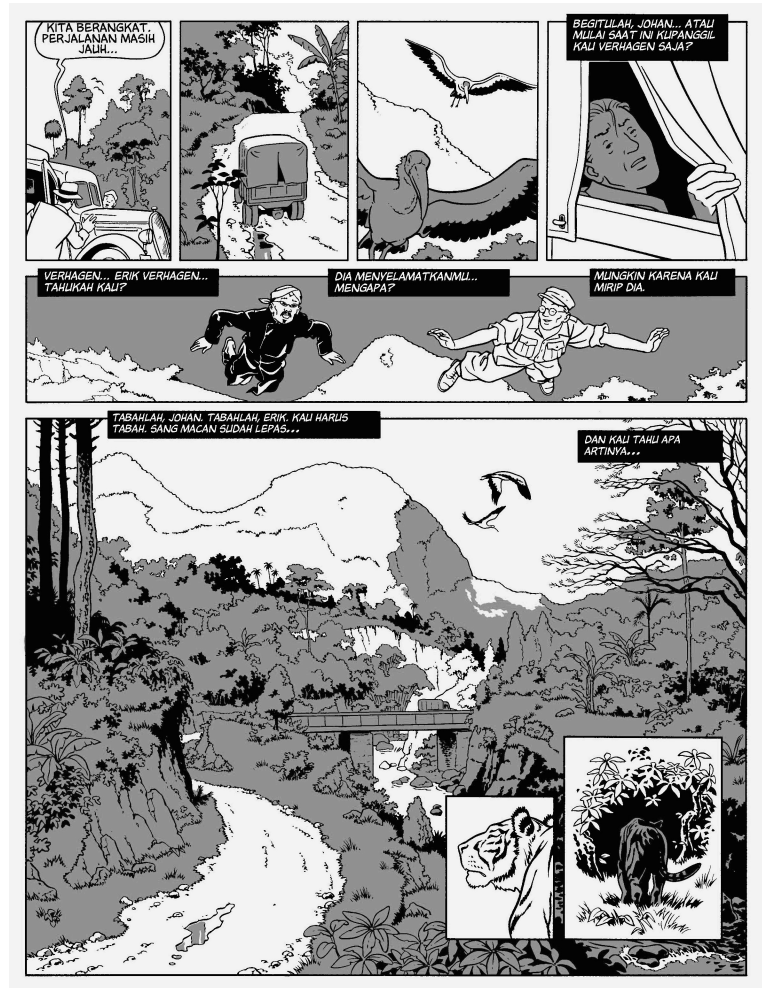

Gambar 4 Pengolahan komposisi warna untuk menampilkan twist cerita; antara kenyataan \& hal surealis, dan antara kejadian masa kini \& cerita masa lalu. Sumber: Dongen, Peter van. (2014). Rampokan Jawa \& Selebes; GPU, h. 75 